Proceeding

Oopen Access

A) CrossMark

\title{
Quality of life among children with cochlear implants
}

\section{Abstract}

Background: Nowadays Kazakhstan is carries out cochlear implants from 2007year for deafness children. Benefit package cover by only monolateral CI. Also Ministry of health for early detection and treatment of children with hearing loss cover newborn hearing screening test. The relevance of our study is to study the quality of life of child with CI.

Aim: To study the quality of life of children after unilateral cochlear implantation.

Material and methods: A literature search was conducted all clinical trial, randomized controlled trial, reviews in the PubMed, Cochrane. Included studies covered a period from last ten years, all child from 0-18years old, limited English language. By discussion of two reviewers we included unilateral CI in children for quality of life and clinical effectiveness.

Results: The literature review shows the effectiveness and improvement in the quality of life of children with a cochlear implant, which is expressed by improving speech recognition and perception in children, also development of lexical, auditory and speech activity was largely due to the variability of communication and the quality of life. Correlations in the communication variable show a direct relationship between the oral message and the quality of life.

Conclusion: The literary review revealed a lack of research on the quality of life of children with CI in Kazakhstan. Our further research involves studying the quality of life of children with CI using a questionnaire EQ5D.

Keywords: quality of life, deafness children, cochlear implants
Volume 9 Issue 2 - 2017

Aigul Medeulova, Lyazzat Kosherbayeva High school of public health and Kazakh National Medical University, Kazakhstan

Correspondence: Aigul Medeulova High school of public health and Kazakh National Medical University, Kazakhstan, Tel +7 7014217765, Email medeulova@bk.ru

Received: November 06, 2017 | Published: November 22, 2017

\section{Acknowledgments}

None.

\section{Conflicts of interest}

Author declares there are no conflicts of interest.

\section{Funding}

None. 